\title{
Dynamic simulation for effective workforce management in new product development
}

\author{
M. Mutingi ${ }^{*}$
}

Department of Mechanical Engineering, University of Botswana, Gaborone, Botswana

\begin{tabular}{|c|c|}
\hline A R T I C L E I N F O & A B S T R A C T \\
\hline $\begin{array}{l}\text { Article history: } \\
\text { Received April 25, } 2012 \\
\text { Accepted } 6 \text { July } 2012 \\
\text { Available online } \\
\text { July } 92012 \\
\text { Keywords: } \\
\text { System dynamics } \\
\text { New product development } \\
\text { Workforce } \\
\text { Knowledge management }\end{array}$ & $\begin{array}{l}\text { Effective planning and management of workforce for new product development (NPD) projects } \\
\text { is a great challenge to many organisations, especially in the presence of engineering changes } \\
\text { during the product development process. The management objective in effective workforce } \\
\text { management is to recruit, develop and deploy the right people at the right place at the right time } \\
\text { so as to fulfill organizational objectives. In this paper, we propose a dynamic simulation model } \\
\text { to address the workforce management problem in a typical NPD project consisting of design, } \\
\text { prototyping, and production phases. We assume that workforce demand is a function of project } \\
\text { work remaining and the current available skill pool. System dynamics simulation concepts are } \\
\text { used to capture the causality relationships and feedback loops in the workforce system from a } \\
\text { systems thinking. The evaluation of system dynamics simulation reveals the dynamic behaviour } \\
\text { in NPD workforce management systems and shows how adaptive dynamic recruitment and } \\
\text { training decisions can effectively balance the workforce system during the NPD process. }\end{array}$ \\
\hline
\end{tabular}

(c) 2012 Growing Science Ltd. All rights reserved.

\section{Introduction}

Due to evolving market conditions, technological advancements, and business growth, dynamic engineering changes in product design and development are inevitable. Decision makers concerned with New Product Development (NPD) strive to make the necessary changes to their product design in order to exploit new market opportunities. In a dynamic and competitive environment, policy makers have to improve product performance at the lowest possible cost in order to remain competitive in the market place and to keep abreast with technology evolution. Industries, such as Information Technology (IT) firms, should always strive to explore new business opportunities for business growth so as to keep abreast with external business competition. In such dynamic and evolving business environment, effective management of workforce and knowledge is a serious challenge to many organisations involved with NPD. In order to remain competitive, organisations that use NPD as a strategic weapon must have a system in place to effectively manage their workforce levels in order to manage their new products effectively. A typical NPD process consists

* Corresponding author

E-mail addresses: michael.mutingi@mopipi.ub.bw (M. Mutingi) 
of several stages, such as opportunity identification, concept development, product design, prototyping and testing, and production. In practice, the process is iterative in nature, such that product design concepts and ideas may necessarily need to be changed during or after the NPD process. These changes are identified and accommodated in the NPD process. Ultimately, the overall performance of the project in terms of lead time, product cost, resource usage, revenue and productivity, may be affected. The management of these engineering changes in a dynamic environment is an essential but complex task (Reddi \& Moon, 2011). Such changes may require workforce retraining in order to regain workforce competence and knowledge. In this regard, proper workforce management tools are essential in order to improve the overall performance of the NPD process.

In respect of the above issues, the current research aims to develop a system dynamics (SD) approach to managing workforce in NPD projects with engineering changes. The specific objectives in this study are: (i) to highlight the causal relationships between various factors in a typical NPD project; (ii) to develop stock and flow models for interacting sectors within the NPD project; and, (iii) to carry out what-if analyses and to draw managerial insights for effective workforce management for NPD projects in a dynamic environment.

The rest of the paper is structured as follows. The next section presents a review of related work, highlighting the concepts leading to the current research. Section 3 presents a system dynamics model for managing NPD workforce. Section 4 provides simulation results together with discussions. Managerial implications and insights are presented in Section 5. Section 6 concludes the paper.

\section{Related literature}

In this section, extant literature in NPD project management is discussed, highlighting important concepts and research points leading to the current research. The current status of the application of SD in modelling NPD and workforce management is also highlighted.

\subsection{New product development}

NPD can be defined as the overall process of producing a new product from concept generation to the market (Khan, 2004) There has been increasing attention to improving the understanding of the management of NPD projects. Nevertheless, because of the dynamic nature of the critical success factors such as time, cost, quality, and dynamic changes, very few NPD projects succeed due to inherent engineering changes that demand dynamic adjustment to the requisite resources such as workforce. Though various researchers have focused their efforts to better understand the NPD process, very little progress has been made in this area. This is attributed to the use of traditional models of the NPD organization that are based on sequential and functional approach to product development and workforce management which often make NPD projects inflexible to change (Wheelwright \& Clark, 1992). These limitations led to the development of a more agile approach to product development (Sterman, 1992; Ford, 1995). Yet, the need for a better understanding of the dynamics of NPD, particularly workforce dynamics, is still a priority in various organizations. In this development, the current research is aimed at developing an improved understanding of the dynamics of product development and workforce dynamics and other factors in the presence of engineering changes within the NPD project.

\subsection{System dynamics in workforce management}

Forrester (1961) pioneered the system dynamics methodology to study the policies of labour source and control labour change. The model was related to the classic manufacturing supply chain model. Sterman (2004) put forward the study to promotion chain and labour force management study, while 
considering such factors as learning curve, mentoring, as well as on-job training. The author then proposed the concept of labour supply chain, and studied the behaviours including hiring and learning. An inventory model was used as the basis for building the labour supply chain model. In the same vein, Coyle (1977) explored a typical problem existing in consulting firms, exploring how best to recruit the right number of trainees and consultants considering the market potential.

\subsection{System dynamics in project management}

Static features of projects have been extensively studied and applied to project management practices. Tools and techniques such as the Work Breakdown Structure, the Critical Path Method (CPM) and Program Evaluation and Review Technique (PERT) have dominated for decades (Halpin \& Woodhead, 1980). In contrast, project managers do not effectively understand or utilize the dynamic features of project structures (Rodrigues \& Bowers, 1996). These dynamic features include feedbacks, time delays, and nonlinear causal relationships among project components. These features combine to cause project systems to behave in complex ways which are difficult to understand, predict, and manage. System Dynamics models provide a useful tool for a more systematic management of these dynamic issues.

There have been a number of applications of SD in project management. For example, Sterman (1992) used System Dynamics modelling for management of large scale engineering and construction projects. Rodrigues and Williams (1998) assessed the impacts of client behaviours on project performance, including schedule restrictions on milestones, high demand on progress reports, delays in approving documents, and changes to work scope throughout the lifecycle. An et al. (2007) presented a system dynamics approach to managing workforce levels in a project management. In comparison, we conclude that traditional models support the project manager in the detailed operational problems within the process, but SD models provide more strategic insights and understanding about the effectiveness of different managerial policies. These two approaches provide complementary support to project management; this suggests it could be of major value to integrate the best of both worlds. In summary, the current research on workforce management fails to provide a systematic view for researchers to explore the overall picture of all workforce management activities. System dynamics is a useful tool to get the insight of the operational mechanism in the workforce management system.

\section{System dynamics simulation for NPD workforce management}

This research is concerned with system dynamics modelling and organizational learning with specific application to workforce management in NPD. SD methodology, originally proposed by Forrester (1961), has been widely applied by a number of researchers and practitioners in various NPD project situations (Coyle, 1977; Morecroft, 1999; Mohapatra et al., 1994; Jessen, 1990; Rodrigues et al., 2006). Causal loop diagramming is used in this research to capture causal linkages inherent between variable. Stocks and flow models, with the aid of relevant difference equations, are used to simulate the NDP process characterised by complex dynamics and engineering changes.

\subsection{Dynamic causal interactions}

The most important step in the SD methodology is the causal loop diagramming which captures the causal linkages between various relevant dynamic factors using the principles of cybernetics. Dynamic factors considered include NPD changes, rework, scheduled time, schedule pressure, training rate, and skill-pool. Ideally, a NPD project begins with an ideal scheduled plan, within a specific scope. In the presence of any discrepancy in workforce, new potential workforce are recruited and trained to improve competency. However, due to market pressure, technological 
evolution, and economic growth, NPD changes are bound to increase. Customers often make multiple requests for technology changes to be included in the product of their choice. This leads to more rework which eventually leads to more NPD work. As a result more skills will be required in order to cover up for the increase work load. By recruitment and training of more competent workforce, competence will be improved and the schedule pressure will be reduced. Nevertheless, rework causes ripple effects on the completion of the project, leading to delays in the completion of the project. We model the NPD process as a dynamic system comprising four distinct phases of NPD work arrival, design, prototyping, production, including rework and engineering change. In this connection, the overall model comprises three interacting sectors as shown in Fig. 1.

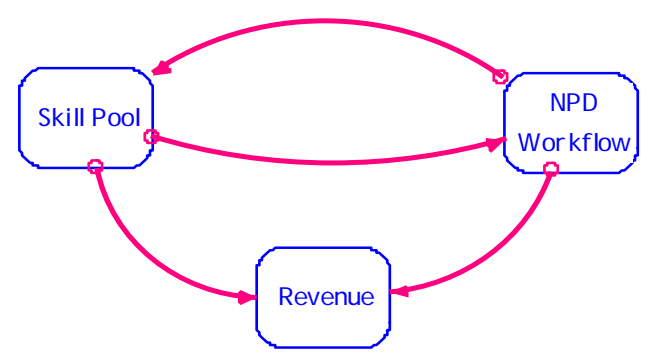

Fig. 1. Sector diagram for NPD workforce management model

\subsection{Stock and flow models}

In this section, we explain the system dynamics model for managing NPD projects with engineering changes. The model developed in this study is a modified version of past models found in Ford (1995), Rodrigues et al. (2006) and (Balaji \& James (2005). More specifically, this SD model seeks to investigate the effects of NPD changes on workforce levels and skills loss. In this connection, the dynamics of NPD management problem was represented by three sub-models as follows,

1. NPD workflow submodel, which pertains to design, prototyping and production;

2. Skill-pool submodel which entails staff recruitment, training and re-training; and

3. Revenue submodel which covers revenue generation and workforce compensation.

Fig. 2 shows the stocks and flows of the NDP workflow submodel. The logic of the submodel involves four stocks, that is, Design_Tasks, Designs, Proto_types as well as Rework. It is assumed that these stocks represent the flow of components of information from NPD concept arrival to design, prototyping and production. The initial work load is the input for the stock Design_Tasks which is performed by the competent staff Skill_Pool. The completed stocks are moved from Design_Tasks to Designs which represent completed design components. The efficiency of the flow of these stocks is determined by the productivity of the competent Skill_Pool. Ideally, these completed design stocks are moved to Proto_types stocks, provided the required quality level is met. The design components that fail to meet the requirements are reworked on by some of the skilled staff so as to improve their standards. Design components that are at the right level of quality trigger the corresponding prototyping process. The aim is to move the prototype components to production, subject to the quality level restraint. It follows that failed prototype components will signal rework on the design components that correspond to those prototype components. It is assumed that the errors in the design components have to be rectified as early as possible, therefore rework is given priority over new design tasks. 


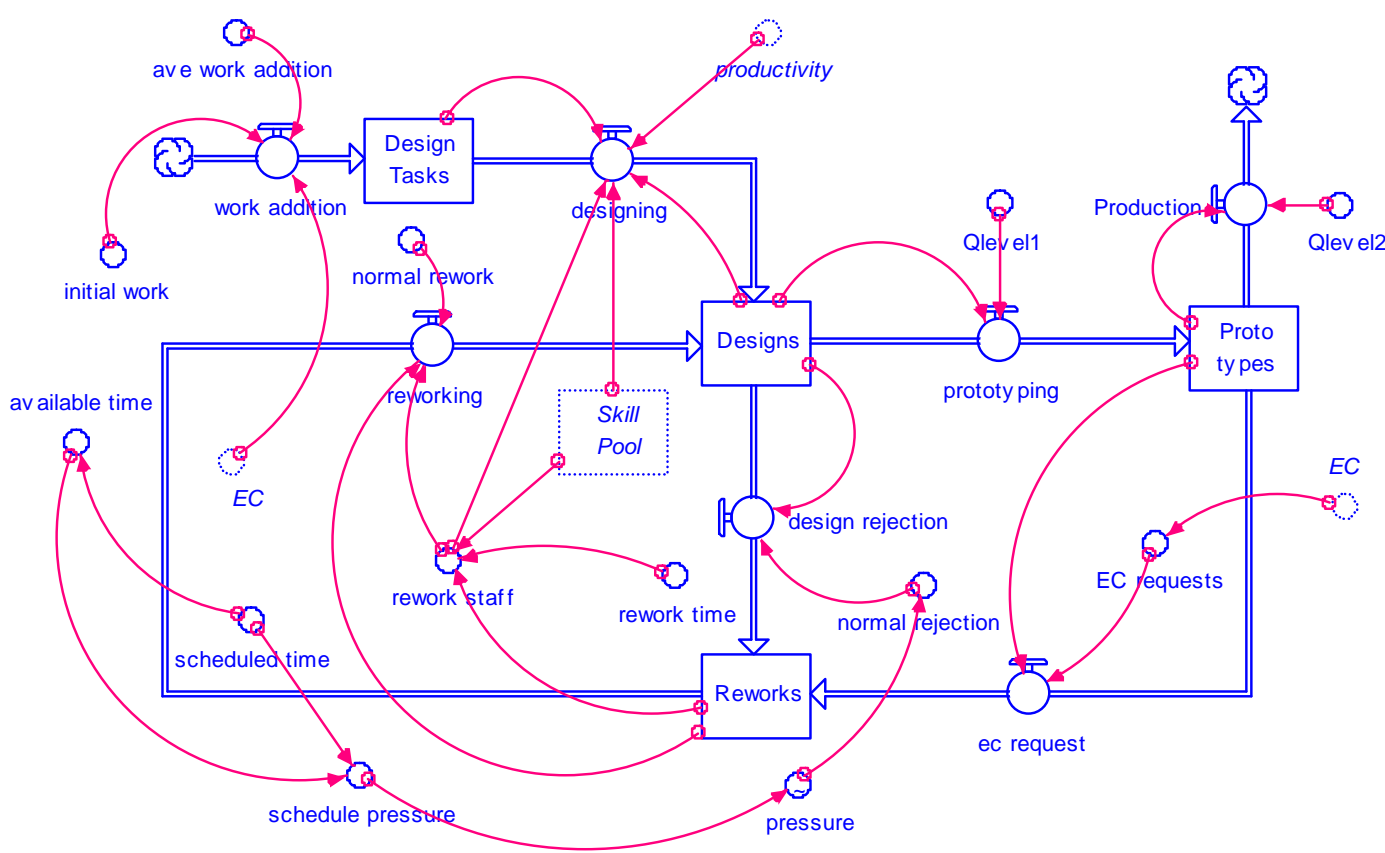

Fig. 2. Workflow dynamics

Fig. 3 illustrates the skill pool submodel. The requisite workforce is obtained from the quotient of initial workflow and the scheduled project time. This is done taking into account the natural attrition rate of the skilled staff. Accordingly, potential staff is hired into Potential_Staff stocks and trained over the planned training time. The training process transforms the staff into Skill_Pool. Occasionally, staff may need retraining so as to improve their competence. This is especially important given that their skills and knowledge may not be adequate following the occurrence of design changes associated with the NPD process. Thus, the staff may lose competence after design changes; therefore, they should regain their skills through retraining.

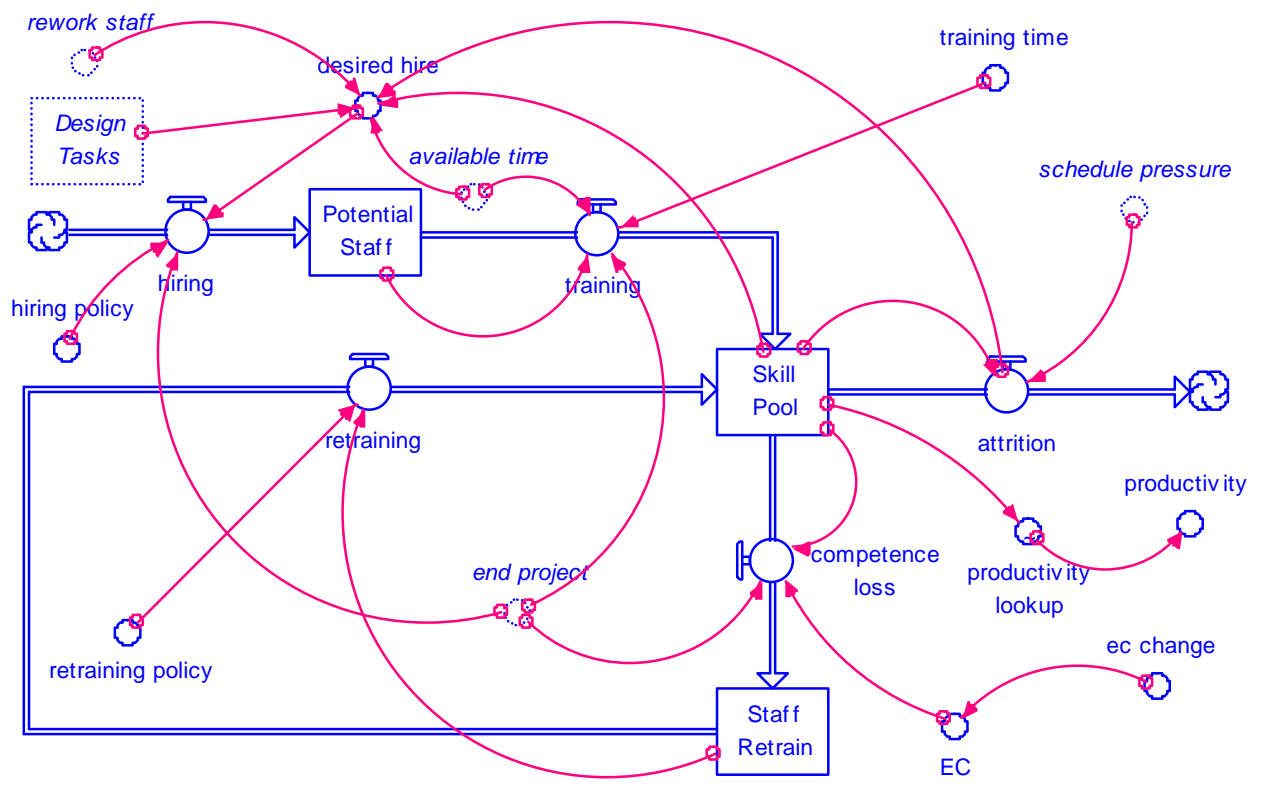

Fig. 3. Skill pool dynamics

Fig. 4 shows a simplified stock diagram for the revenue submodel, consisting of Revenue and Finished_Work stocks. Here, we assume that revenue is generated according to the rate of production of the finished work, which is fully dependent on the available workforce. Therefore, stocks of 
revenue are influenced by production rate and depleted by staff compensation rate. Both skilled and potential staff is compensated from the generated revenue.

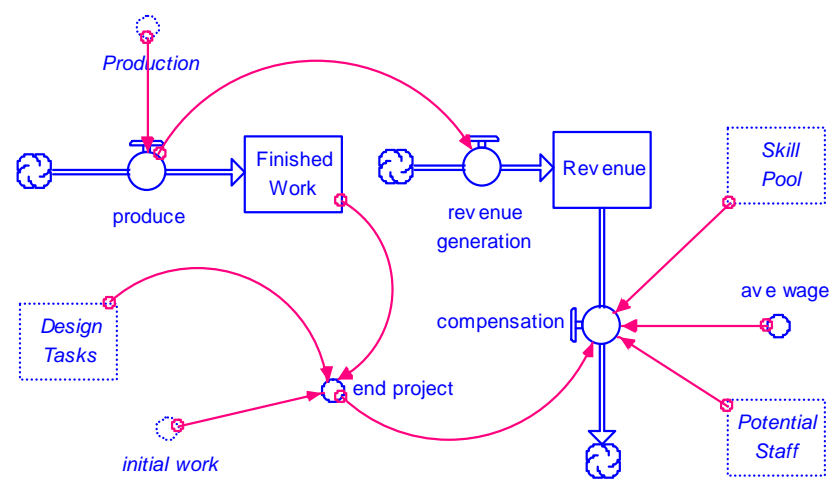

Fig. 4. The revenue submodel

Using the proposed NPD workforce model, the decision maker can make use of the various input control variables such as hiring policy, engineering change, training time and re-training time. Therefore, the model can be used to answer "what-if" questions in regards to formulation of policies that affect workforce decisions. Table 1 shows the policy variable variables available for the decision maker.

\section{Table 1}

Input control variables

\begin{tabular}{lll}
\hline No. & Control variable & Description \\
\hline 1. & hiring policy & average time taken to hire new staff \\
2. & training time & time taken to train new staff \\
3. & retraining policy & time taken to retrain existing staff \\
4. & ec change & average engineering change \\
\hline
\end{tabular}

\section{Simulation results and discussion}

In this section, a summary of the problem situation used for the simulation experiment is presented. Consider an NPD project with design work of 100 man-months to be completed over a planning horizon of 24 months. During the NPD process, single or multiple engineering changes are expected at time $t=10$ and $t=15$ months. Skill pool requirements are to be adjusted on a monthly basis. The training period for new staff is assumed to be one month on average. Any identified rework is given priority over project work in process, and all the rework should be completed in one month. As the available time decreases, the schedule pressure increases and this in turn increases the rejection rate. Assume that the average wage per skill pool staff is \$500 per month. The production output brings revenue at a rate of $\$ 5000$ per unit.

\subsection{Base experiments}

For the base experiments, no engineering changes are expected; this is the most desired or ideal case where no engineering changes occur. Therefore, for the base case, the average engineering change, ec_change $=0$. The model is run over a simulation period of 24 months, while observing the behaviour of skill pool, production rate, revenue generation, and the relative variation of remaining design tasks and finished work. Fig. 5 shows the variation of the graphical behaviour of skill pool, production rate, revenue generation, design tasks remaining and finished work. As illustrated by Fig. 
5 (a), the workforce level increases smoothly due to gradual increase in demand for skills as the NPD project progresses, accumulating work in progress.

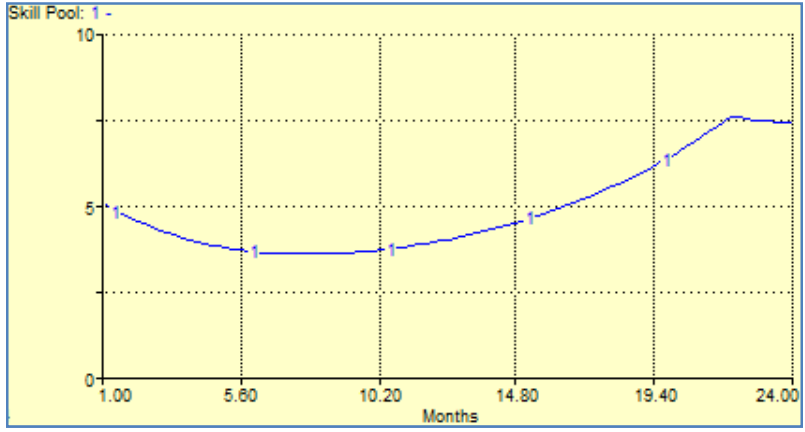

(a)

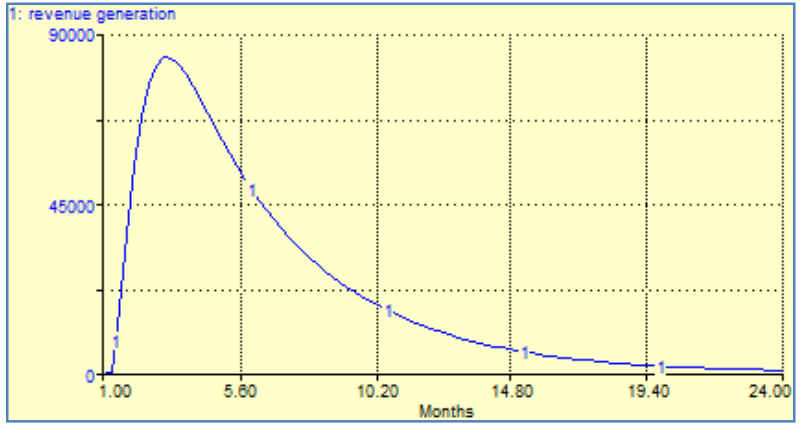

(c)

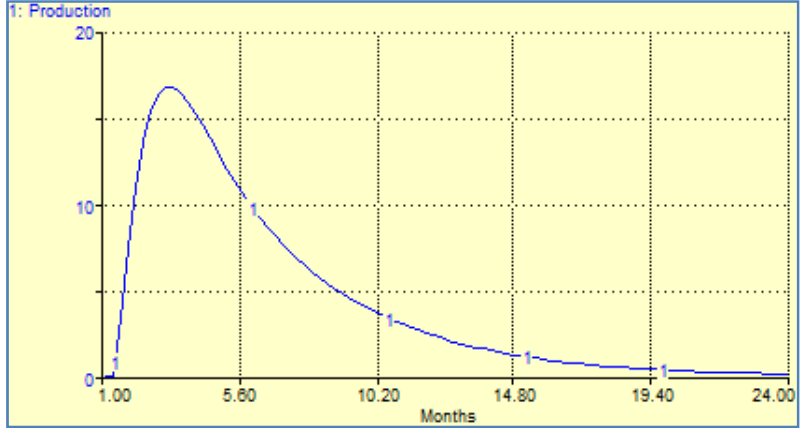

(b)

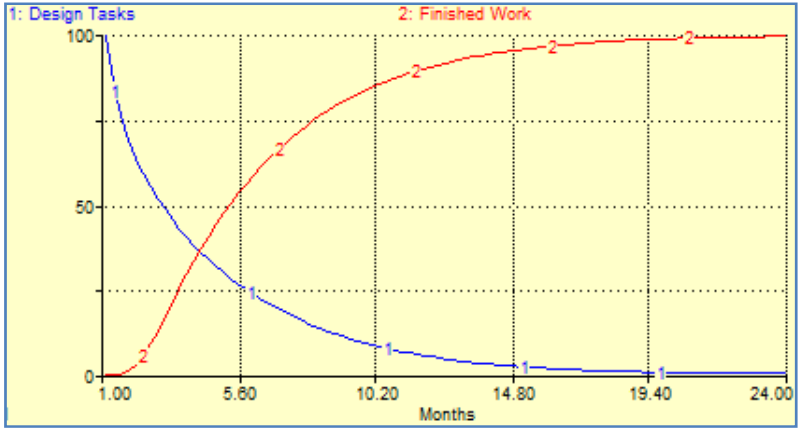

(d)

Fig. 5. Base dynamic simulation results

However, as the project approached completion time at time $t=20$ (see Fig. 5 (d)), recruitment decreases towards zero. The slow steady decrease in the skill pool from time $t=20$ is attributed to gradual attrition. Fig. 5 (b) and (c) show the variation of production and revenue generation, respectively; these vary proportionally as the product development progresses. The next set of experiments provides sensitivity analysis to simulate the behaviour of the model in the presence of multiple requests for engineering change.

\subsection{Sensitivity analysis}

Three sets of simulation experiments were conducted in order to analyse the skill pool behaviour over the planning period of 24 months;

1. vary hiring policy from 1 to 2.5 in steps of 0.5 months;

2. vary the magnitude of a single engineering change from 0 to $60 \%$ in steps of $20 \%$, and;

3. vary the magnitude of multiple engineering changes from 0 to $60 \%$ in steps of $20 \%$.

Here, varying the hiring policy from 1 to 2.5 essentially means that the average hiring time was increased in steps of 0.5 months.

Fig. 6 depicts the behaviour of skill pool over the planning horizon when the hiring policy is varied from 1.0 to 2.5 months. Graphs 1, 2, 3 and 4 correspond to hiring policy 1.0, 1.5, 2.0, and 2.5 respectively. In general, the level of skill pool decreases as hiring policy increases. However, the completion of the project is delayed when hiring policy increases. For instance, as demonstrated by graph 1 and 4, the completion times are 22 and 23.75, respectively. We infer from this scenario that though increased hiring intervals result in lower workforce levels, project completion is delayed. Therefore, the decision maker needs to dynamically determine the hiring policy while considering 
other key issues such as desired project completion time as well as the target revenue generation rate. Thus, system dynamics simulation tools can assist the decision maker in policy evaluation and optimization.

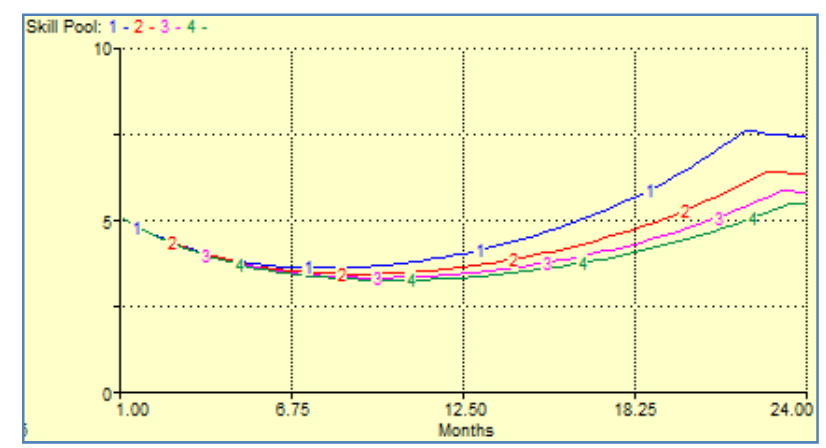

Fig. 6. Skill pool behaviour with increasing hiring policy

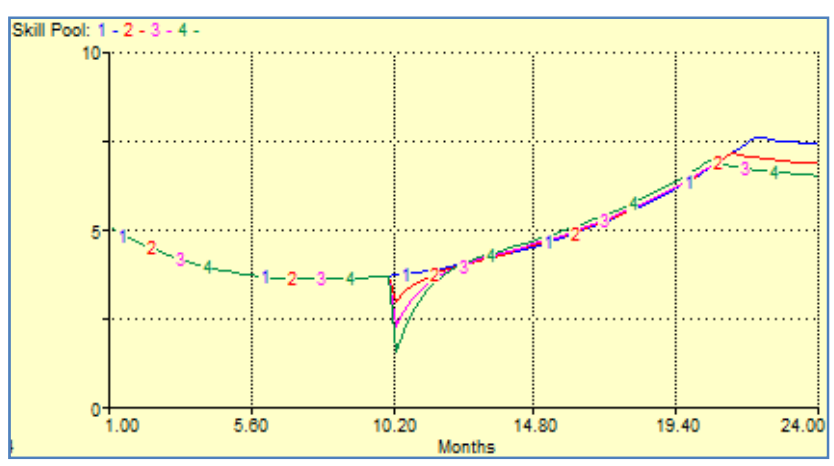

Fig. 7. Skill pool behaviour with increasing engineering change

Fig. 7 shows the results of "what-if" experiments as engineering change was increased from 0 to $60 \%$ in steps of $20 \%$. It can be seen that as engineering change is increased to $60 \%$, the final skill pool size decreases. However, for the period between the engineering change and project completion, the transient skill pool level tends to be higher with higher values of engineering changes. As a result, the project is completed earlier than later due to additional trained and retrained staff. This demonstrates that dynamic decision making is critical in the presence of complex dynamic interactions between hiring, training and retraining of staff. Dynamic simulation tools are essential for robust policy formulation. In the presence of multiple engineering changes, when engineering changes are introduced at different times over the product development process, the effects of those changes over skill pool level are amplified. Two changes were introduced, one at time $t=10$, and another at time $t$ $=15$. In addition, the average percentage change was varied in steps of $20 \%$ from $0 \%$ to $60 \%$ while observing the behaviour of the system in terms of skill pool level. Again, the simulation experiment was run over a period of 40 months.

Fig. 8 shows the simulation results when increasing multiple engineering changes were introduced. Curve 1 refers to the ideal case that assumes that no engineering change will be requested. With an average change of $20 \%$, curve 2 shows dips at time $t=10$ and $t=15$. This results from staff retraining and additional work due to engineering change requests and rework. However, the curve shows that the NPD project was completed on time. As expected, the final skill pool level is slightly lower than with the case of a single engineering. Additionally, project completion time was slightly shorter due to retraining and additional staff.

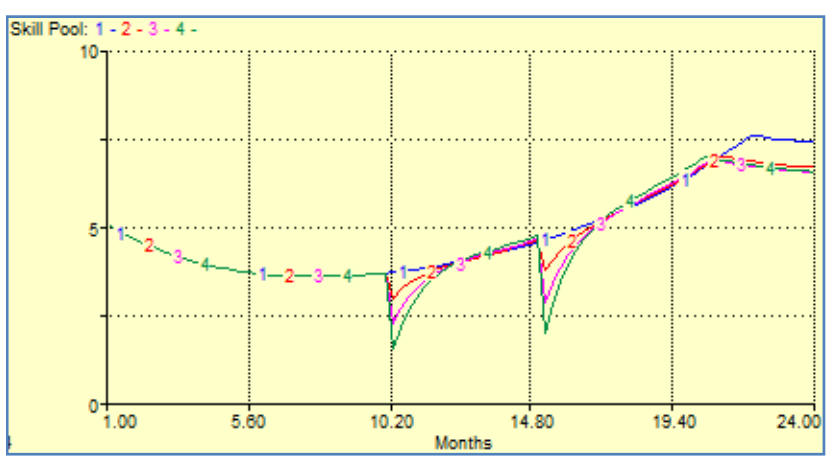

Fig. 8. Skill pool behaviour with increasing multiple engineering changes

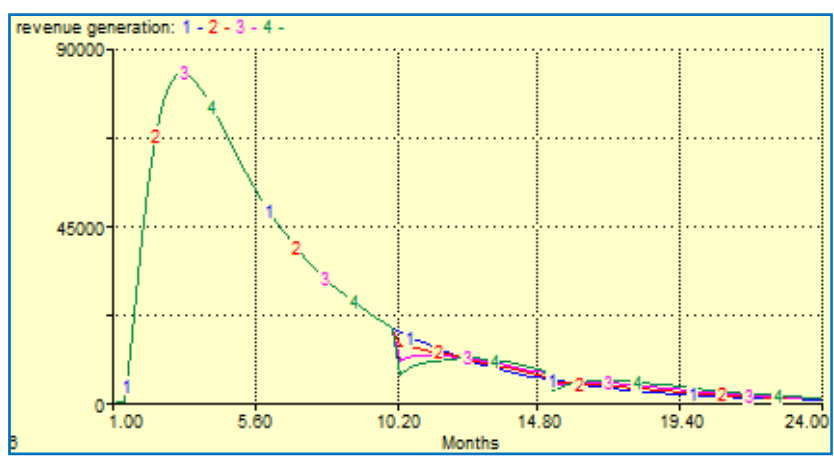

Fig. 9. Revenue generation behaviour with increasing multiple engineering changes

The same analysis goes with curves 3 and 4 as engineering change increased to $40 \%$ and $60 \%$, respectively. The project was completed on time, howbeit with increased skill pool retraining and hiring in order to regain competence lost through multiple changes. 
Fig. 9 depicts the dynamics of revenue generation rate as the engineering change is varied from $0 \%$ to $60 \%$. Again, the base scenario (0\% change) depicted by curve 1 is an ideal case where there are no engineering change requests, and therefore no revenue losses. Conversely, curve 2 shows dips at time $t=10$ and $t=15$, resulting from staff retraining and staff shortage. However, immediately after the introduction of changes, revenue generation increases beyond the ideal case. This is attributed to dynamic staff recruitment and retraining which add more competence to the skill pool. In the same vein, curves 3 and 4 demonstrate the dynamics of revenue generation as engineering change is increased to $40 \%$ and $60 \%$, respectively. Though curves 2,3 and 4 resulted in revenue losses, the curves show that the NPD project was completed on time.

From the above sensitivity analysis, we infer that the higher the percentage change, the more the work additions and the more the skills hiring, training and retraining. Additionally, the higher the number of engineering changes, the higher the hiring, training and retraining activities. Though engineering changes introduce transient losses in production and revenue generation rates due to competence loss, hiring training and retraining brings more knowledge and competence, specifically when multiple changes occur. This in turn is a competitive strategic weapon for the organization in the long term.

\section{Managerial implications}

This research brings considerable knowledge and understanding to decision makers concerned with workforce, technology, facility management aspects. Technology managers need to envision the skills, technology and business aspects of the NPD process, from a systems view point. This requires enhanced organisational learning and flexibility in order to enable collaboration between innovators, human resources managers, and facility managers. With system dynamics tools, the organisation can synthesize a systems-based, rather than a silo-based decision making approach. In summary, the key managerial insights drawn from this study are:

- a collaborative dynamic approach, involving human resource, facility, and product managers, is essential for effective workforce management in NPD;

- increased collaborative involvement between interested parties enhances knowledge-sharing for effective hiring, training, and retraining decisions;

- dynamic hiring, training and retraining policies, synthesized from a systems dynamics viewpoint are more effective than silo decisions.

- dynamic hiring, training and retraining are an investment to the organisation which yields returns in terms of competence and enhanced revenue generation in the long term.

With a proper application of these integrative managerial practices, organisations can effectively manage workforce and knowledge in NPD, even in the presence of multiple engineering changes.

\section{Conclusions}

In NPD projects, such as in Information Technology industry, effective management of workforce in the presence of engineering changes is a critical issue. Dynamic causal linkages involving customer demands, technology evolution, global competition, short product life cycles, cause dynamic complexities to the determination of future workforce levels.

In this research, we demonstrated the effectiveness of the system dynamics tool in formulating strategies and policies for workforce management in NPD projects. The proposed SD model in this study provides a tool for answering "what-if" analysis on factors influencing workforce and 
knowledge management. The results strongly indicate that there is need for effective dynamic formulation of policies in regards to the management of skills competence in industry. This is especially so, in the presence of anticipated multiple engineering changes. With proper estimation of parameter values from past data, the simulation model forms a decision support tool for the policy maker to evaluate dynamic recruitment, training and retraining policies, given various interacting factors. Therefore, with past data, the model can be calibrated and be used for making informed decisions. Suggestions and insights presented in this research provide better practices for effective management of workforce in new product development projects.

\section{References}

An, L., Ren, C., Jeng, J.J., \& Lee, Y.M. (2007). Effective life cycle management via system dynamics modelling and simulation. Proceedings of the 2007 Winter Simulation Conference S. G. Henderson, B. Biller, M.-H. Hsieh, J. Shortle, J. D. Tew, and R. R. Barton, eds.

Balaji, J., \& James, R.B. (2005). Project dynamics with applications to change management and earned value tracking. System Dynamics Society International Conference 2005, Boston, MA.

Coyle, R.G. (1977). Management System Dynamics. John Wiley \& Sons, London.

Ford, D. (1995). The dynamics of project management: an investigation of the impacts of project process and coordination on performance. doctoral thesis, MIT, USA.

Forrester, J.W. (1961). Industrial Dynamics. Productivity Press, Cambridge, MA.

Halpin, D.W., \& Woodhead, R.W. (1980). Construction Management. New York: John Wiley \& Sons.

Jessen, S.A. (1990). The motivation of project managers, a study of variation in Norwegian project managers' motivation and demotivation by triangulation of methods. doctoral thesis, The Henley Management College and Brunel University.

Kahn, K.B. (2004). PDMA Handbook of New Product Development. $2^{\text {nd }}$ ed., John Wiley, New York, NY.

Mohapatra, P.K.J., Mandal, P., \& Bora, M.C. (1994). Introduction to System Dynamics Modelling, Universities Press, Hyderabad.

Morecroft, J.D.W. (1999). Management attitudes, learning and scale in successful diversification: a dynamic and behavioural resource system view. Journal of Operational Research Society, 50, 315-36.

Reddi, K.R., \& Moon, Y.B. (2011). System dynamics modelling of engineering change management in a collaborative environment. International Journal of Advanced Manufacturing Technology, 55(9), 1225-1239.

Rodrigues A., \& Williams, T. M. (1998). System dynamics in project management: assessing the impacts of client behaviour on project performance. Journal of the Operational Research Society, 49(1), 2-15.

Rodrigues, A., \& Bowers, J. (1996). System dynamics in project management: a comparative analysis with traditional methods. System Dynamics Review, 12(2), 121-139.

Rodrigues, L.L.R, Dharmaraj, N., \& Rao, B.R.S. (2006). System dynamics approach for change management in new product development. Management Research News, 29(8), 512-523.

Sterman, J.D. (1992). System dynamics modelling for project management. Sloan School of Management, Massachusetts Institute of Technology [Online], 7 May, Available: http://web.mit.edu/jsterman/www/SDG/project.pdf, [7 May 2012].

Sterman, J.D. (2004). Business Dynamics: Systems Thinking and Modelling for a Complex World. McGraw-Hill Companies Inc., New York, NY.

Wheelwright, S.C., \& Clark, K.B. (1992). Revolutionizing Product Development, Quantum Leaps in Speed, Efficiency, and Quality. The Free Press, New York, NY. 